\title{
Consumo, digestibilidade e excreção de uréia e derivados de purinas em vacas de diferentes níveis de produção de leite ${ }^{1}$
}

\section{Mário Luiz Chizzotti ${ }^{2}$, Sebastião de Campos Valadares Filho ${ }^{3}$, Rilene Ferreira Diniz Valadares ${ }^{4}$, Fernanda Helena Martins Chizzotti ${ }^{2}$, Marcos Inácio Marcondes ${ }^{5}$, Mozart Alves Fonseca ${ }^{6}$}

\author{
${ }^{1}$ Parte da tese de Mestrado do primeiro autor parcialmente financiada pelo CNPq e pela FAPEMIG. \\ 2 Doutorando em Zootecnia - UFV. \\ ${ }^{3}$ Departamento de Zootecnia - UFV. Bolsista CNPq. \\ ${ }^{4}$ Departamento de Medicina Veterinária - UFV. Bolsista CNPq. \\ ${ }^{5}$ Mestrando em Zootecnia - UFV. \\ ${ }^{6}$ Graduando em Agronomia - UFV. Bolsista de Iniciação Científica - CNPq
}

RESUMO - Objetivou-se avaliar o efeito do nível de produção de leite sobre o consumo e a digestibilidade dos nutrientes (MS, MO, EE, PB, FDNcp e CNF corrigidos), o consumo de NDT, a produção de proteína microbiana e a excreção de compostos nitrogenados na urina. Foram avaliadas as concentrações de N uréico no soro (NUS) e no leite (NUL) de animais de diferentes níveis de produção de leite. Foram comparadas as metodologias de coletas de urina spot e total para quantificação do fluxo de $\mathrm{N}$ microbiano. Quinze vacas holandesas foram alocadas em delineamento inteiramente casualizado, com três tratamentos, de acordo com a produção de leite: 5,88 (baixa); 18,54 (média) e 32,6 kg de leite/dia (alta). A dieta foi constituída de silagem de milho fornecida à vontade e $1 \mathrm{~kg}$ de concentrado para cada $3 \mathrm{~kg}$ de leite produzido. Os consumos de todos os nutrientes, exceto FDNcp, foram maiores nos animais mais produtivos. As digestibilidades de MS e MO e o teor de NDT não diferiram entre os tratamentos, mas as digestibilidades da PB e da FDNcp foram influenciadas pelo nível de produção, sendo maior e menor, respectivamente, nos animais de alta produção. Os teores de NUS e NUL e a excreção de compostos nitrogenados na urina foram altamente correlacionados e superiores nos animais mais produtivos, indicando que a concentração ótima varia com o nível de produção de leite. A produção microbiana não diferiu entre as metodologias de coleta spot e total de urina, sendo inferior nos animais menos produtivos. Assim, a coleta de urina spot pode ser utilizada para estimar a excreção de compostos nitrogenados na urina e a produção de proteína microbiana no rúmen.

Palavras-chave: FDNcp, $\mathrm{N}$ uréico no leite, $\mathrm{N}$ uréico no soro, proteína microbiana, coleta spot

\section{Intake, digestibility and nitrogen metabolism in Holstein cows with different milk production levels}

\begin{abstract}
The objective of this trial was to evaluate the effect of milk production level on intake, digestibility of nutrients, microbial protein synthesis, and nitrogen $(\mathrm{N})$ metabolism in Holstein cows. It was also of particular interest to compare spot urine sampling and total urine collection as methodologies to quantify yield of microbial $\mathrm{N}$ using purine derivatives (PD) as indirect microbial markers. Fifteen Holstein cows were grouped by milk yield (5.88 $\mathrm{kg} /$ day: LOW treatment; $18.54 \mathrm{~kg} / \mathrm{day}$ : MEDIUM treatment; and $32.6 \mathrm{~kg} / \mathrm{day}$ : HIGH treatment) and data analyzed as a completely randomized design. Animals were fed ad libitum corn silage plus one $\mathrm{kg}$ of concentrate per each three $\mathrm{kg}$ of milk produced. Except for NDF corrected for ash and protein $\left(\mathrm{NDF}_{\mathrm{ap}}\right)$, intake of all remaining nutrients was increased by milk yield. Digestibilities of DM and OM and dietary TDN content did not differ among treatments. However, digestibility of CP was higher and that of $\mathrm{NDF}_{\text {ap }}$ was lower on the greatest milk yielding cows ( $\mathrm{HIGH}$ treatment). Concentrations of milk urea $\mathrm{N}$ and serum urea $\mathrm{N}$ as well as urinary $\mathrm{N}$ excretion were all greatest in the HIGH treatment and were also highly correlated with milk yield. Microbial protein synthesis estimated by PD was lowest on cows in the LOW treatment and did not differ when either spot urine sampling or total urine collection was used. Therefore, spot urine sampling can be used to estimate urinary excretion of nitrogenous compounds and microbial protein synthesis in Holstein cows with different production levels.
\end{abstract}

Key Words: microbial protein, milk urea nitrogen, NDFap, serum urea nitrogen, spot sampling

\section{Introdução}

A alta correlação produção animal $\times$ ingestão de ali- mentos decorre do fato de que o consumo de alimentos é o principal determinante do ingresso de nutrientes para o atendimento das exigências de mantença e produção dos 
animais. A acurácia da predição do consumo de MS é fundamental na formulação de dietas para o correto atendimento das exigências nutricionais.

A maior parte dos aminoácidos absorvidos pelos ruminantes é proveniente da proteína microbiana sintetizada no rúmen. Os métodos utilizados para medir a quantidade de compostos nitrogenados microbianos baseiam-se em indicadores microbianos internos, como bases purinas e ácido 2,6 diaminopimélico (DAPA), e externos, como o ${ }^{35} \mathrm{~S}$ e o ${ }^{15} \mathrm{~N}$ (Broderick \& Merchen, 1992). Entretanto, estes métodos requerem a utilização de animais cirurgicamente adaptados e a determinação do fluxo de MS no abomaso, sendo recentemente desenvolvidas metodologias baseadas em marcadores metabólicos da síntese microbiana. O uso dos derivados de purina (DP) para estimar a síntese microbiana no rúmen foi primeiramente proposto por Blaxter \& Martin (1962), citados por Fujihara et al. (1987). Por este método, assume-se que o fluxo duodenal de ácido nucléico é essencialmente de origem microbiana e que, após digestão intestinal, as bases purinas (adenina e guanina) são catabolizadas e excretadas proporcionalmente à quantidade absorvida. Os DP excretados podem ser de origem endógena, proveniente do catabolismo dos ácidos nucléicos do animal (estimado em função do peso deste) ou derivados da degradação das purinas microbianas absorvidas (Chen \& Gomes, 1992).

O método baseado na excreção de DP requer coleta total de urina. O volume urinário tem sido obtido por meio de coletas com sondas por períodos de 24 a 120 horas, porém, pesquisas têm sido realizadas para estimar a excreção diária de urina utilizando-se uma amostra coletada ao longo do dia (coleta spot), possibilitando a utilização deste método em situações a campo e facilitando as coletas em experimentos (Valadares et al., 1999; Oliveira et al., 2001). Estimando-se a excreção diária de creatinina por meio do peso vivo, o volume urinário pode ser calculado pela concentração de creatinina na amostra spot.

Os teores de nitrogênio uréico no soro (NUS) e nitrogênio uréico no leite (NUL) têm sido utilizados para obtenção de informações adicionais sobre o perfil da nutrição protéica de ruminantes, envolvendo a resposta metabólica destes animais a determinada dieta. Evitam-se assim as perdas econômicas advindas do fornecimento inadequado de proteína na dieta (devido aos elevados custos destes suplementos) e os possíveis prejuízos produtivos, reprodutivos e ambientais. A concentração de uréia pode ser avaliada no soro (NUS) ou no plasma sangüíneo (NUP), equilibrando-se facilmente entre o soro ou plasma e o leite. Quando NUL ou NUS excedem 19-20 mg/dL, a taxa de concepção pode ser reduzida em aproximadamente $20 \%$ (Butler et al., 1998).
Considerando que o incorreto balanceamento protéico na dieta resulta em aumentos na concentração de uréia sérica e na excreção urinária de compostos nitrogenados, esforços têm sido feitos para estimar a excreção urinária de nitrogênio (NU) a partir do NUL e determinar a produção microbiana por meio da coleta spot de urina.

Diante do exposto, este trabalho foi realizado com os seguintes objetivos: avaliar o efeito do nível de produção de leite sobre o consumo e a digestibilidade dos nutrientes, a produção de proteína microbiana, as concentrações de $\mathrm{N}$ uréico no soro e no leite (NUS e NUL) e a excreção de N, uréia e derivados de purinas na urina; analisar o efeito da presença de cinzas e proteína na FDN sobre a digestibilidade da FDN e dos CNF; identificar as relações entre as concentrações de NUS, NUL e amônia ruminal e a excreção urinária de N; e comparar as estimativas da produção de proteína microbiana obtidas por meio da coleta spot ou da coleta total de urina.

\section{Material e Métodos}

O experimento foi realizado na Unidade de Ensino, Pesquisa e Extensão em Gado de Leite (UEPE-GL) do Departamento de Zootecnia da Universidade Federal de Viçosa (UFV), em Viçosa-MG, sendo a fase de campo realizada durante o mês de abril de 2003 .

Utilizaram-se 15 vacas holandesas em sistema de confinamento total, mantidas em baias individuais com cocho e bebedouro, contidas por cabresto. O estudo foi conduzido em um delineamento inteiramente casualizado, com três tratamentos (níveis de produção de leite) e cinco repetições: tratamento baixa - cinco vacas com produção de leite de 5,88 $\pm 1,69 \mathrm{~kg} / \mathrm{dia}$; tratamento média - cinco vacas com produção de leite de $18,54 \pm 4,56 \mathrm{~kg} / \mathrm{dia}$ e tratamento alta - cinco vacas com produção de leite de $32,60 \pm 4,34 \mathrm{~kg} / \mathrm{dia}$.

O período experimental teve duração de nove dias. As vacas dos tratamentos baixa, média e alta, estavam, em média, com 45, 33 e 17 semanas de lactação, pesavam 670, 578 e $584 \mathrm{~kg}$, respectivamente, e já estavam adaptadas às dietas. A alimentação, na forma de mistura completa, foi equivalente à do rebanho da UEPE-GL-UFV - silagem de milho fornecida à vontade e $1 \mathrm{~kg}$ de concentrado para cada $3 \mathrm{~kg}$ da média diária de leite produzido na semana anterior - sendo fornecida diariamente às 7 e $16 \mathrm{~h}$, permitindo sobras de, no máximo, $5 \%$. As sobras foram retiradas pela manhã, quantificadas, amostradas e armazenadas. As vacas foram ordenhadas mecanicamente, duas vezes ao dia, registrando-se a produção de leite.

A composição média dos alimentos utilizados é descrita na Tabela 1. O concentrado foi composto de fubá de milho 
(27,2\%), sorgo moído (20\%), farelos de trigo (5\%), de algodão $(5 \%)$ e de soja $(37,8 \%)$, uréia $(1 \%)$, sulfato de amônio $(0,1 \%)$, sal comum $(0,84 \%)$, fosfato bicálcico $(1,7 \%)$, calcário $(1 \%)$ e mistura mineral $(0,36 \%)$ contendo cloreto de potássio $(83,15 \%)$, sulfato de cobre $(2,77 \%)$, sulfato de cobalto $(0,17 \%)$, sulfato de zinco $(13,86 \%)$ e selenito de sódio $(0,05 \%)$.

Nos dias 5 e 7 , foram coletadas amostras de fezes diretamente do reto, às $18 \mathrm{e} 6 \mathrm{~h}$, respectivamente. As amostras foram pré-secas em estufa de ventilação forçada $\left(60^{\circ} \mathrm{C}\right.$ por 72 horas) e trituradas em moinho de facas com peneira de $1 \mathrm{~mm}$ para formação de uma amostra composta por animal, elaborada com base no peso seco de cada subamostra.

A fibra em detergente ácido indigestível (FDAi) foi utilizada para estimativa da produção de MS fecal, conforme proposto por Cochran et al. (1986), sendo determinada nas amostras de sobras, fezes e dos alimentos utilizados nas dietas.

$\mathrm{Na}$ ordenha da tarde do $5 \underline{0}$ dia e na da manhã do $6^{\circ}$ dia do período experimental, foram coletadas amostras de leite para formação de uma amostra composta, proporcional à produção em cada ordenha, para análise dos teores de gordura, segundo Pregnolatto \& Pregnolatto (1985). A produção de leite foi corrigida para 3,5\% de gordura, conforme a equação: produção de leite corrigida $=(0,432+0,1625 \times \%$ de gordura do leite) $\times$ produção de leite (Tyrrell \& Reid, 1965). Uma alíquota de $10 \mathrm{~mL}$ de leite foi diluída com $5 \mathrm{~mL}$ de ácido tricloroacético a $25 \%$, sendo filtrada em papel-filtro e congelada para posterior determinação dos níveis de uréia e alantoína no leite desproteinizado (Valadares et al., 1999).

Alíquotas de $50 \mathrm{~mL}$ de urina (amostra spot) foram obtidas de todas as vacas no $6 \underline{0}$ dia do período experimental, aproximadamente 4 horas após a alimentação, durante

Tabela 1 - Composição nutricional dos alimentos utilizados nas dietas

Table 1 - Chemical composition of dietary feeds

\begin{tabular}{|c|c|c|}
\hline & \multicolumn{2}{|c|}{$\begin{array}{l}\text { Alimento } \\
\text { Feed }\end{array}$} \\
\hline & $\begin{array}{l}\text { Silagem de milho } \\
\text { Corn silage }\end{array}$ & $\begin{array}{c}\text { Concentrado } \\
\text { Concentrate }\end{array}$ \\
\hline MS (\%) $(D M, \%)$ & 25,34 & 89,02 \\
\hline MO (\% da MS) (OM, \% of DM) & 94,95 & 92,03 \\
\hline $\mathrm{PB}(\%$ da $\mathrm{MS})(C P, \%$ of $D M)$ & 6,67 & 28,69 \\
\hline PDR $(\% \mathrm{~N}$ total $)(R D P, \%$ total $N)$ & 75,04 & 63,87 \\
\hline NIDN (\% $\mathrm{N}$ total) (NDIN, \% total $N)$ & 16,07 & 10,81 \\
\hline NIDA $(\% \mathrm{~N}$ total $)($ ADIN, \% total $N)$ & 9,20 & 6,59 \\
\hline $\mathrm{EE}(\%$ da MS) $(E E, \%$ of $D M)$ & 3,70 & 2,77 \\
\hline FDN (\% da MS) (NDF, \% of $D M)$ & 56,57 & 13,16 \\
\hline FDNcp (\% da MS) (NDFap, \% of DM) & 53,19 & 11,70 \\
\hline CNF (\% da MS) (NFC, \% of DM) & 27,91 & 49,21 \\
\hline CNFcp (\% da MS) (NFCap, \% of DM) & 31,39 & 50,67 \\
\hline FDA (\% da MS) $(A D F, \%$ of $D M)$ & 35,60 & 6,89 \\
\hline Lignina (\% da MS) (Lignin, \% of DM) & 5,08 & 1,22 \\
\hline FDAi (\% da MS) (iADF, \% of DM) & 18,87 & 1,70 \\
\hline
\end{tabular}

micção estimulada por massagem na vulva. A urina foi filtrada e alíquotas de $10 \mathrm{~mL}$ foram diluídas imediatamente em $40 \mathrm{~mL}$ de ácido sulfúrico a $0,036 \mathrm{~N}$ para evitar destruição bacteriana dos derivados de purinas e precipitação do ácido úrico. Uma amostra de urina pura foi armazenada para determinação dos compostos nitrogenados totais, de uréia e creatinina. Concomitantemente, foram obtidas amostras de sangue por punção da veia coccígea, em tubos de ensaio com gel separador e acelerador de coagulação. O sangue foi imediatamente centrifugado a $5.000 \mathrm{rpm}$ por 15 minutos para obtenção do soro, que foi armazenado em congelador para posterior determinação da concentração de uréia.

No 8 o dia, foi realizada coleta de urina de cada animal, durante 24 horas, utilizando-se cateter de Folley n ${ }^{\circ} 26$ (duas vias, com balão de $50 \mathrm{~mL}$ ), introduzido via uretra até a bexiga. Na extremidade externa do cateter, foi acoplada mangueira de polietileno, que conduziu a urina até recipientes plásticos contendo $500 \mathrm{~mL}$ de ácido sulfúrico a $20 \%$. Ao término das 24 horas de coleta, a urina foi pesada e homogeneizada para obtenção de duas amostras (pura e diluída) por animal, conforme descrito para a amostra spot.

Amostras de conteúdo ruminal foram coletadas 4 horas após a alimentação matinal, no 9을a, por meio de uma sonda introduzida pelo esôfago, para determinação do $\mathrm{pH}$ e da concentração de amônia no líquido ruminal, conforme técnica de Fenner (1965), adaptada por Vieira (1980).

O processamento das amostras de alimentos, sobras e fezes e a determinação dos teores de MS, cinzas, nitrogênio total, nitrogênio insolúvel em detergente ácido (NIDA), nitrogênio insolúvel em detergente neutro (NIDN), EE e FDA foi realizado conforme descrito por Silva \& Queiroz (2002). A FDN foi determinada pela técnica da autoclave, após incubação com amilase termoestável, segundo Rennó et al. (2002), e os teores de cinzas e N da FDN foram estimados conforme descrito por Silva \& Queiroz (2002). A FDN corrigida (FDNcp) foi obtida descontando-se os teores de cinzas e $\mathrm{N}$ insolúveis em detergente neutro. Os CNF corrigidos (CNFcp) foram calculados por meio da equação (Weiss, 1999): $\mathrm{CNFcp}=100-(\% \mathrm{~PB}+\% \mathrm{EE}+$ \% Cinzas + \%FDNcp); e os CNF foram calculados pela mesma equação, porém utilizando-se a FDN sem correção. Em virtude da presença de uréia, os CNFcp do concentrado foram calculados como proposto por Hall (2000): $\mathrm{CNF} c \mathrm{p}=100-[(\% \mathrm{~PB}-\% \mathrm{~PB}$ derivada da uréia $+\%$ de uréia $)$ $+\% \mathrm{FDNcp}+\% \mathrm{EE}+\%$ cinzas]. O consumo de NDT foi calculado como PB digestível + FDNcp digestível + CNFcp digestível + (2,25 $\times$ EE digestível) (Sniffen et al., 1992).

A determinação da concentração de uréia na urina, no soro e no leite desproteinizado foi realizada segundo o método diacetil modificado utilizando-se kits comerciais. 
A creatinina foi determinada nas amostras de urina obtidas pelas coleta total e spot, por meio de kits comerciais (Labtest). A excreção diária de creatinina $(24,05 \mathrm{mg} / \mathrm{kgPV} / \mathrm{dia})$ foi obtida pelo produto do volume excretado e da concentração de creatinina urinária da coleta total (Chizzotti, 2004). A concentração de creatinina na amostra spot foi utilizada para estimar o volume urinário e a excreção dos demais compostos urinários para comparação dos valores obtidos na amostra spot aos observados na coleta total.

Os níveis de alantoína na urina e no leite desproteinizado e os de ácido úrico na urina foram determinados pelo método colorimétrico, conforme metodologia de Fujihara et al. (1987), descrita por Chen \& Gomes (1992).

A excreção total de DP foi calculada pela soma das quantidades de alantoína e ácido úrico excretadas na urina e da quantidade de alantoína excretada no leite, expressas em mmol/dia.

As purinas microbianas absorvidas (Pabs, mmol/dia) foram calculadas a partir da excreção de derivados de purinas (DP, mmol/dia), por meio da equação Pabs = $\left(\mathrm{DP}-0,236 \times \mathrm{PV}^{0,75}\right) / 0,84$, em que 0,84 é a recuperação de purinas absorvidas como derivados de purina e $0,236 \times$ $\mathrm{PV}^{0,75}$, a excreção endógena de derivados de purina (Orellana Boero et al., 2001). Foram avaliadas também as purinas absorvidas, considerando-se a excreção endógena de 0,512 $\times \mathrm{PV}^{0,75}$ e a recuperação de 0,70 encontradas por GonzalezRonquillo et al. (2003).

A síntese ruminal de compostos nitrogenados (Nmic, gN/dia) foi calculada com base nas purinas absorvidas (Pabs, mmol/dia), utilizando-se a equação (Chen \& Gomes, 1992): Nmic $=(70 \times$ Pabs $) /(0,83 \times 0,134 \times 1.000)$, em que 70 é o conteúdo de $\mathrm{N}$ nas purinas $(\mathrm{mgN} / \mathrm{mol}) ; 0,134$, a relação $\mathrm{N}$ purina: $\mathrm{N}$ total nas bactérias (Valadares et al., 1999); e 0,83 , a digestibilidade intestinal das purinas microbianas.

Os teores de proteína degradável no rúmen (PDR) foram calculados conforme recomendações do NRC (2001). As taxas de passagem da digesta ruminal foram calculadas conforme proposto pelo NRC (2001), para cada animal, obtendo-se, em média, 6,06; 5,32 e 4,23\%/h, respectivamente, para os animais de alta, média e baixa produção. O teor de PDR foi calculado a partir dos coeficientes de degradabilidade ruminal da PB relatados por Chizzotti (2004).

Os resultados foram avaliados por meio de análises de variância e pelos testes de médias (Newmann Keuls a 5\% de probabilidade) e regressões utilizando-se o Sistema de Análises Estatísticas e Genéticas - SAEG (UFV, 1998). Aplicou-se o teste t a 5\% de probabilidade para comparação das metodologias de coleta de urina e das equações utilizadas no cálculo das purinas absorvidas.

\section{Resultados e Discussão}

Constam na Tabela 2 os valores da produção e composição do leite, o consumo médio de nutrientes, as médias dos coeficientes de digestibilidade aparente dos nutrientes, o teor de NDT das dietas, as comparações entre as médias das digestibilidades aparentes da FDN e dos CNF, corrigidos ou não para cinzas e proteína, e os coeficientes de variação obtidos em cada tratamento. As porcentagens de volumoso nas dietas fornecidas foram 55,87; 68,03 e 84,7, respectivamente, para vacas de alta, média e baixa produção. $\mathrm{O}$ consumo de todos os nutrientes, exceto FDNcp, foi influenciado significativamente pela produção de leite. Pelas teorias de regulação do consumo (NRC, 2001), os animais consomem alimentos para atender às exigências de energia; assim, o consumo é controlado pela produção de leite. Isto pode ser evidenciado em experimentos com somatotropina bovina (BST), nos quais o aumento da produção eleva o consumo de MS, evidenciando que o consumo acompanha as exigências nutricionais dos animais. As equações de predição de consumo de MS propostas pelo NRC (2001) superestimaram em 17, 16 e $40 \%$ o consumo de MS pelos animais de alta, média e baixa produção, respectivamente (22,1; 18,2 e 15,1 kg MS/dia).

Apenas as digestibilidades de PB, EE e FDNcp foram significativamente diferentes entre os tratamentos. Embora os animais tenham consumido diferentes proporções de volumoso e concentrado, em decorrência do fornecimento de concentrado de acordo com a produção de leite, não foram observadas diferenças nas digestibilidades de MS, MO e CNF e na porcentagem de NDT das dietas, o que parece estar associado ao maior consumo, que pode ter ocasionado maior taxa de passagem e reduzido o tempo de permanência dos alimentos no trato gastrintestinal, diminuindo a digestibilidade da dieta, que é resultante da interação taxa de degradação $\times$ taxa de permanência da digesta nos locais de digestão (Van Soest, 1994). A menor digestibilidade da FDNcp nos animais de alta produção pode ser atribuída ao aumento da proporção de concentrado na dieta e ao menor tempo de permanência da digesta no ambiente ruminal, visto que a degradação da FDNcp é lenta e altamente influenciada pelo tempo de contato com as enzimas bacterianas. Ítavo et al. (2002) observaram que, em novilhos, as digestibilidades total e ruminal da FDN reduziram de forma linear com o aumento do nível de concentrado na dieta e atribuíram essa diferença à competição entre bactérias amilolíticas e fibrolíticas, visto que os microrganismos amilolíticos se desenvolvem mais rapidamente e apresentam vantagem competitiva quanto ao uso do nitrogênio, limitando a disponibilidade 
Tabela 2 - Médias e coeficientes de variação (CV) para as produções de leite $(\mathrm{PL})$, o teor de gordura do leite $(G)$, as produções de leite corrigidas para $3,5 \%$ de gordura (PLG), os consumos diários e os coeficientes de digestibilidade total dos nutrientes, os teores de NDT das dietas e os consumos, em \%PV, de MS e FDNcp obtidos nos diferentes níveis de produção de leite

Table 2 - Means and coefficients of variation (CV) for milk yield (MY), milk fat (F) content, 3.5\% fat-corrected milk (FCM), intake and apparent total tract digestibility of nutrients, dietary TDN content, and intake of DM and NDFap expressed as $\% B W$, according to different milk yield levels

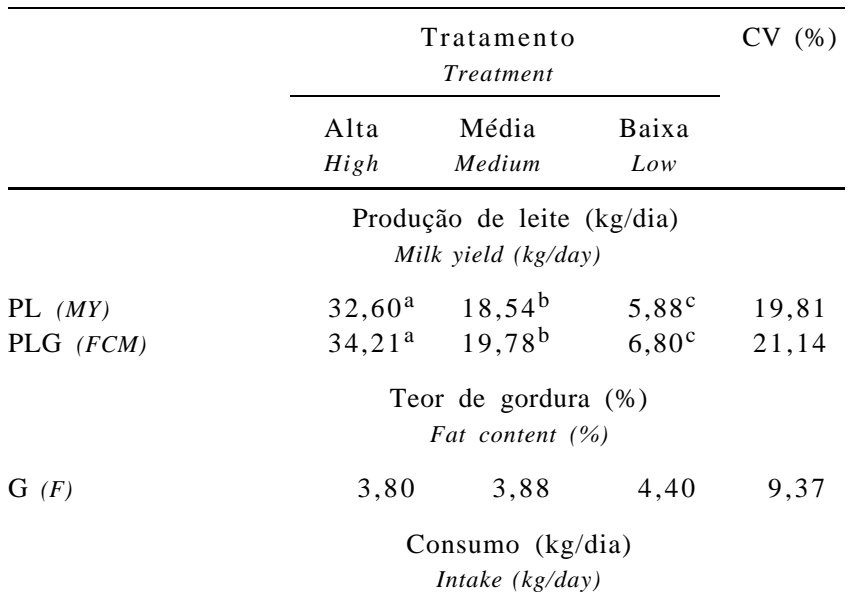

$\begin{array}{lrrrr}\text { MS (DM) } & 18,91^{\mathrm{a}} & 15,61^{\mathrm{b}} & 10,93^{\mathrm{c}} & 12,20 \\ \text { MO (OM) } & 17,68^{\mathrm{a}} & 14,65^{\mathrm{b}} & 10,33^{\mathrm{c}} & 12,26 \\ \text { PB (CP) } & 3,27^{\mathrm{a}} & 2,26^{\mathrm{b}} & 1,14^{\mathrm{c}} & 15,65 \\ \text { PDR (RDP) } & 2,23^{\mathrm{a}} & 1,61^{\mathrm{b}} & 0,85^{\mathrm{c}} & 14,56 \\ \text { EE (EE) } & 0,66^{\mathrm{a}} & 0,55^{\mathrm{b}} & 0,41^{\mathrm{c}} & 11,36 \\ \text { FDNcp (NDFap) } & 6,20 & 5,87 & 4,96 & 13,20 \\ \text { CNFcp (NFCap) } & 7,72^{\mathrm{a}} & 6,07^{\mathrm{b}} & 3,85^{\mathrm{c}} & 12,85\end{array}$

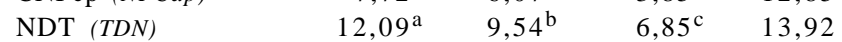

Consumo $(\% \mathrm{PV} /$ dia $)$ Intake (\%BW/day)

MS (DM)
FDNcp (FDNap)

$\begin{array}{llll}3,24^{\mathrm{a}} & 2,70^{\mathrm{b}} & 1,64^{\mathrm{c}} & 10,56 \\ 1,06^{\mathrm{a}} & 1,02^{\mathrm{a}} & 0,75^{\mathrm{b}} & 13,70\end{array}$

Coeficiente de digestibilidade (\%)

Coefficient of digestibility (\%)

$\begin{array}{lrrrr}\text { MS (DM) } & 61,43 & 58,22 & 59,29 & 6,60 \\ \text { MO (OM) } & 63,44 & 60,69 & 61,89 & 6,62 \\ \text { PB (CP) } & 71,18^{\mathrm{a}} & 65,68^{\mathrm{b}} & 58,52^{\mathrm{c}} & 5,93 \\ \text { EE (EE) } & 84,09^{\mathrm{a}} & 78,80^{\mathrm{b}} & 87,49^{\mathrm{a}} & 4,42 \\ \text { FDN (NDF) } & 39,33^{\mathrm{b}, \mathrm{A}} & 47,27^{\mathrm{a}, \mathrm{A}} & 49,63^{\mathrm{a}, \mathrm{A}} & 11,98 \\ \text { FDNcp (NDFap) } & 42,38^{\mathrm{b}, \mathrm{B}} & 51,44^{\mathrm{a}, \mathrm{B}} & 53,37^{\mathrm{a}, \mathrm{B}} & 11,72 \\ \text { CNF (NFC) } & 80,80^{\mathrm{A}} & 72,60^{\mathrm{A}} & 78,84^{\mathrm{A}} & 8,74 \\ \text { CNFcp (NFCap) } & 75,72^{\mathrm{B}} & 66,72^{\mathrm{B}} & 71,38^{\mathrm{B}} & 8,75\end{array}$

Valor energético das dietas (\%MS)

Dietary energy value $(\% D M)$

NDT (TDN)

$63,86 \quad 61,05 \quad 62,83$

6,14

a, b, c Médias na linha seguidas por diferentes letras minúsculas diferem pelo teste Newman Keuls a $5 \%$ de probabilidade.

A, B Para FDN e FDNcp ou CNF e CNFcp, médias na coluna seguidas por diferentes letras maiúsculas diferem pelo teste $t$ a $5 \%$ de probabilidade.

$a, b, c$ Means in a row followed by different lowercase letters differ by Newman Keuls test at $5 \%$ of probability.

A,, B ForNDF and NDFap or NFC and NFCap, means in columns followed by different capital letters differ by t test at $5 \%$ of probability. de nitrogênio aos microrganismos celulolíticos. Segundo Coelho da Silva \& Leão (1979), valores de pH inferiores a 6,0 podem acarretar inibição das bactérias fibrolíticas. Neste experimento, o $\mathrm{pH}$ (superior a 6,0 ) foi mais baixo nos animais mais produtivos (Tabela 5).

A digestibilidade da PB da dieta foi maior nas vacas mais produtivas, provavelmente em virtude do maior consumo deste nutriente por estes animais, pois a maior ingestão de $\mathrm{N}$ resulta em progressiva diminuição da proporção de $\mathrm{N}$ endógeno nos compostos nitrogenados fecais, aumentando a digestibilidade aparente da PB (Van Soest, 1994).

A correção da FDN (FDNcp) aumentou, em média, $8,04 \%$ a digestibilidade da FDN, indicando que a falta de correção da FDN para cinzas e proteína subestima a digestibilidade da FDN. A falta de correção da FDN superestimou em 7,94\% a digestibilidade dos CNF, sugerindo que as digestibilidades da FDN e dos CNF sem correção sejam multiplicadas por 1,08 e 0,92 , respectivamente. Ao realizar o mesmo tipo de comparação, Rennó et al. (2002) verificaram, em novilhos, que a presença de cinzas e proteína na FDN subestimou a digestibilidade da FDN e superestimou a dos CNF. Esses autores sugeriram que a digestibilidade da FDN seja multiplicada por 1,04 e a dos CNF por 0,96. Ressalta-se, no entanto, que, independentemente do uso da FDN e dos CNF corrigidos, o NDT das dietas não é alterado.

As excreções diárias de $\mathrm{N}$ total e $\mathrm{N}$ uréico na urina e as concentrações de $\mathrm{N}$ uréico no soro, na urina e no leite e de $\mathrm{N}-\mathrm{NH}_{3}$ no rúmen são apresentadas na Tabela 3. Foram observadas maiores concentrações e excreções de $\mathrm{N}$ uréico no soro e no leite nos animais de maior produção, evidenciando a correlação entre estes parâmetros. Foram observados teores médios de 17,30; 14,48 e 10,43\% de PB na MS ingerida pelos animais de alta, média e baixa produção, respectivamente. Valadares et al. (1997) e Valadares et al. (1999) demonstraram que a concentração sérica de uréia está positivamente relacionada à ingestão de $\mathrm{N}$.

De acordo com Santos et al. (2001), quanto maior a degradabilidade da proteína dietética, maior a produção de amônia ruminal e, conseqüentemente, maiores as concentrações de uréia no soro e no leite e as perdas nitrogenadas na urina e no leite. O maior consumo de proteína degradável (Tabela 2) pelos animais mais produtivos resultou em maiores concentrações de amônia no rúmen e, conseqüentemente, as concentrações de NUS e NUL e as excreções de $\mathrm{N}$ uréico e $\mathrm{N}$ total na urina e no leite aumentaram. 
Os balanços de $\mathrm{N}$, obtidos por $\mathrm{N}$ ingerido menos $\mathrm{N}$ excretado no leite, na urina e nas fezes, foram de 163, $101 \mathrm{e}$ $46 \mathrm{~g} / \mathrm{dia}$, respectivamente, para as vacas de alta, média e baixa produção. Tanto em $\%$ do $\mathrm{N}$ ingerido quanto em $\%$ do $\mathrm{N}$ absorvido, o balanço de $\mathrm{N}$ foi similar $(\mathrm{P}>0,05)$ entre os tratamentos, com médias de 28,33 e $43,29 \%$, respectivamente, sugerindo retenções de $\mathrm{N}$ similares entre os animais de diferentes níveis de produção.

As altas correlações entre os consumos de proteína degradável no rúmen (CPDR) e de proteína bruta (CPB) com a excreção diária de $\mathrm{N}$ na urina permitiram ajustar as seguintes equações de regressão: $\mathrm{NU}(\mathrm{g} / \mathrm{dia})=105,27 \times$ $\operatorname{CPDR}(\mathrm{kg} / \mathrm{dia})-38,23\left(\mathrm{r}^{2}=0,90\right)$ e NU $(\mathrm{g} / \mathrm{dia})=68,00 \times \mathrm{CPB}$ $(\mathrm{kg} / \mathrm{dia})-24,92\left(\mathrm{r}^{2}=0,90\right)$.

Segundo Butler et al. (1998), a variação horária de NUL segue o mesmo padrão de NUS, podendo ser um parâmetro útil para avaliar a utilização da proteína em relação à sua ingestão. Esses autores, avaliando amostras obtidas em 19 rebanhos de alta produção de leite, obtiveram valor médio de NUL de 17,7 mg/dL (variando de 14,4 a 20,2 mg/dL).

Tabela 3 - Médias e coeficientes de variação (CV) para as concentrações de $\mathrm{N}$ amoniacal no rúmen $\left(\mathrm{N}-\mathrm{NH}_{3}\right)$ e de nitrogênio uréico no soro (NUS) e no leite (NUL) e excreções de $\mathrm{N}$ total no leite (NL) e na urina (NU) e de nitrogênio uréico no leite (NUL) e na urina (NUU) nos diferentes níveis de produção de leite

Table 3 - Means and coefficients of variation (CV) for rumen ammonia N $\left(\mathrm{NH}_{3}-\mathrm{N}\right)$, serum urea $\mathrm{N}(\mathrm{SUN})$, milk urea $\mathrm{N}(\mathrm{MUN})$ and daily excretion of total $\mathrm{N}$ on milk (NM) and urine (NU) and of urea $N$ on milk (UNM) and urine (UNU) according to different milkyield levels

\begin{tabular}{cccc}
\hline \multicolumn{3}{c}{ Tratamento } & CV (\%) \\
\cline { 2 - 3 } Treatment & \\
Alta & Média & Baixa \\
High & Medium & Low \\
\hline
\end{tabular}

Concentração $(\mathrm{mg} / \mathrm{dL})$

Concentration $(\mathrm{mg} / \mathrm{dL})$

\begin{tabular}{|c|c|c|c|c|}
\hline $\mathrm{N}-\mathrm{NH}_{3}$ & $13,34^{\mathrm{a}}$ & $10,98^{\mathrm{a}}$ & $3,84^{b}$ & 31,55 \\
\hline NUS (SUN) & $20,01^{\mathrm{a}}$ & $13,41^{b}$ & $9,04^{b}$ & 24,01 \\
\hline \multirow[t]{2}{*}{ NUL (MUN) } & $22,70^{\mathrm{a}}$ & $14,16^{b}$ & $10,04^{b}$ & 26,19 \\
\hline & \multicolumn{3}{|c|}{$\begin{array}{c}\text { Excreção diária } \\
\text { Daily excretion }\end{array}$} & \\
\hline $\mathrm{NL}(\mathrm{g})(N M, g)$ & $15,89^{a}$ & $9,23^{\mathrm{b}}$ & $3,35^{\mathrm{c}}$ & 33,33 \\
\hline NUL $(g)(U N M, g)$ & $7,57^{\mathrm{a}}$ & $2,72^{\mathrm{b}}$ & $0,59^{b}$ & 52,15 \\
\hline $\mathrm{NU}(\mathrm{g})(N U, g)$ & $194,79^{a}$ & $127,58^{b}$ & $56,77^{\mathrm{c}}$ & 30,41 \\
\hline NUU $(g)$ & $170,48^{\mathrm{a}}$ & $111,52^{b}$ & $38,78^{\mathrm{c}}$ & 34,59 \\
\hline \multicolumn{5}{|l|}{$U N U(g)$} \\
\hline $\mathrm{NU} \quad(\mathrm{mg} / \mathrm{kgPV})$ & $333,69^{a}$ & $215,39^{b}$ & $84,74^{\mathrm{c}}$ & 25,25 \\
\hline \multicolumn{5}{|l|}{$N U(\mathrm{mg} / \mathrm{kgBW})$} \\
\hline NUU (mg/kgPV) & $291,23^{\mathrm{a}}$ & $188,86^{b}$ & $58,13^{\mathrm{c}}$ & 29,50 \\
\hline
\end{tabular}

$N U(\mathrm{mg} / \mathrm{kgBW})$

a, b, c Médias na linha seguidas por diferentes letras diferem pelo teste Newman Keuls a $5 \%$ de probabilidade.

a, $b, c$ Means in a row followed by different letters differ by Newman Keuls test at $5 \%$ of probability.
Broderick (1995) sugeriu que valores de NUL de 12 a $17 \mathrm{mg} / \mathrm{dL}$ indicam adequado balanceamento de PDR e de energia fermentada no rúmen.

Considerando que o incorreto balanceamento de proteína e aminoácidos na dieta resulta em aumentos na concentração de uréia sérica e na excreção urinária de compostos nitrogenados, esforços têm sido feitos para estimar a excreção urinária de N (NU) a partir do NUL ou NUS, que podem ser facilmente determinados. Com os dados obtidos, foram ajustadas equações de regressão para determinar a excreção de NU a partir das concentrações de NUS e NUL e do peso vivo $(\mathrm{PV})$ : $\mathrm{NU}(\mathrm{g} / \mathrm{dia})=9,1267 \times$ $\mathrm{NUS}(\mathrm{mg} / \mathrm{dL})\left(\mathrm{r}^{2}=0,73\right) ; \mathrm{NU}(\mathrm{g} / \mathrm{dia})=0,0151 \times \mathrm{NUS}(\mathrm{mg} / \mathrm{dL}) \times$ $\mathrm{PV}(\mathrm{kg})\left(\mathrm{r}^{2}=0,69\right) ; \mathrm{NU}(\mathrm{g} / \mathrm{dia})=8,1941 \times \mathrm{NUL}(\mathrm{mg} / \mathrm{dL})$ $\left(\mathrm{r}^{2}=0,73\right) \mathrm{eNU}(\mathrm{g} / \mathrm{dia})=0,0135 \times \mathrm{NUL}(\mathrm{mg} / \mathrm{dL}) \times \mathrm{PV}(\mathrm{kg})\left(\mathrm{r}^{2}=0,69\right)$.

Jonker et al. (1998) recomendaram a equação: $\mathrm{NU}(\mathrm{g} / \mathrm{dia})=12,54 \times \mathrm{NUL}(\mathrm{mg} / \mathrm{dL})$, que superestimou a excreção de NU em 46, 39 e 122\%, respectivamente, pelas vacas de alta, média e baixa produção. Kauffman \& St-Pierre (2001), no entanto, propuseram que a regressão incluísse o peso vivo $(\mathrm{PV})$ e sugeriram a equação: $\mathrm{NU}(\mathrm{g} / \mathrm{dia})=$ $0,0259 \mathrm{PV}(\mathrm{kg}) \times \mathrm{NUL}(\mathrm{mg} / \mathrm{dL})$, que também superestimou a excreção de N na urina em 77, 68 e $207 \%$ pelas vacas de alta, média e baixa produção, respectivamente.

Foram verificadas altas correlações entre NUS e NUL, sendo ajustada a seguinte equação: NUS $=0,8948 \times \mathrm{NUL}$ $\left(r^{2}=0,96\right)$. Utilizando dados de 419 vacas em lactação, Broderick (1995) encontrou a seguinte equação relacionando NUP e NUL: NUL = 0,587 $\times$ NUP + 5,57 $\left(\mathrm{r}^{2}=0,74\right)$, a qual subestimou em 24 e $5 \%$ e superestimou em $8 \%$ o NUL nas vacas de alta, média e baixa produção, respectivamente.

Foi desenvolvida a seguinte equação para estimar a concentração de $\mathrm{N}$ amoniacal no rúmen $\left(\mathrm{N}-\mathrm{NH}_{3}\right)$ a partir da concentração de NUS: N-NH $3=0,7407 \times$ NUS $-1,1078$ $\left(r^{2}=0,67\right)$.

São apresentados na Tabela 4 as médias e os coeficientes de variação para as excreções de DP, os compostos nitrogenados microbianos e a eficiência microbiana obtidos pela coleta total de urina durante 24 horas, e o $\mathrm{pH}$ ruminal 4 horas após a alimentação matinal nos três níveis de produção de leite. Foram constatadas menores excreções de alantoína e ácido úrico e, portanto, menor excreção de derivados de purinas, menor absorção intestinal de purinas e menor produção de proteína microbiana no rúmen dos animais de baixa produção. Variações na síntese microbiana são associadas a mudanças no suprimento de energia e proteína ao animal hospedeiro, em virtude de mudanças na produção de leite, o que justifica a correlação produção de leite $\times$ excreção de derivados de purina relatada por GonzalezRonquillo et al. (2003). 
A excreção de alantoína no leite foi similar entre os níveis de produção de leite. Em trabalho realizado por Gonda \& Lindberg (1997), as excreções de alantoína no leite foram superiores quando o consumo de MS ou a porcentagem de concentrado na dieta aumentaram. A alantoína no leite representou apenas 0,$31 ; 0,30$ e $0,20 \%$ da excreção total de DP nas vacas de alta, média e baixa produção e elevado coeficiente de variação (75\%), não sendo, portanto, apropriada para estimar a excreção diária de DP. Gonda \& Lindberg (1997) relataram valores de 0,63 a $1,34 \%$ de alantoína no leite em relação à alantoína urinária. Esses autores notaram que essa proporção foi variável em diferentes produções de leite e concluíram que a avaliação apenas da excreção de alantoína láctea não foi um bom indicador da produção microbiana.

Tabela 4 - Médias e coeficientes de variação (CV) obtidos em coleta total do volume diário de urina (VUR), das excreções urinárias de alantoína (ALA) e ácido úrico $(A c U)$, de alantoína no leite (ALAL), de derivados de purinas totais (DP), da porcentagem de alantoína nos DP (ALA:DP), das purinas absorvidas (Pabs), do nitrogênio microbiano (Nmic), da eficiência microbiana (Efic) e do pH ruminal obtido 4 horas após a alimentação $(\mathrm{pH})$ nos diferentes níveis de produção de leite

Table 4 - Means and coefficients of variation (CV), obtained by total urine collection, for daily urinary volume (UV), urinary excretions of allantoin (ALLA) and uric acid (UAC), milk allantoin (MALLA), total purine derivatives $(P D)$, allantoin:PD ratio (ALLA:PD), absorbed purines (absP), microbial nitrogen (micN) synthesis, microbial efficiency (Effic) and ruminal $\mathrm{pH}$ four hours after feeding $(\mathrm{pH})$ according to different milk yield levels

\begin{tabular}{|c|c|c|c|c|}
\hline & \multicolumn{3}{|c|}{$\begin{array}{c}\text { Tratamento } \\
\text { Treatment }\end{array}$} & \multirow[t]{2}{*}{$\mathrm{CV}(\%)$} \\
\hline & $\begin{array}{l}\text { Alta } \\
\text { High }\end{array}$ & $\begin{array}{l}\text { Média } \\
\text { Medium }\end{array}$ & $\begin{array}{l}\text { Baixa } \\
\text { Low }\end{array}$ & \\
\hline VUR (L/dia) & 21,59 & 21,63 & 10,30 & 52,05 \\
\hline $\begin{array}{l}U V \text { (L/day) } \\
\text { ALA (mmol/dia) }\end{array}$ & $323,70^{\mathrm{a}}$ & $268,48^{\mathrm{a}}$ & $160,18^{\mathrm{b}}$ & 23,70 \\
\hline $\begin{array}{l}\text { ALLA (mmol/day) } \\
\text { AcU ( } \mathrm{mmol} / \mathrm{dia}) \\
\text { UAC (mmol/day) }\end{array}$ & $39,28^{\mathrm{a}}$ & $27,75^{\mathrm{b}}$ & $14,28^{\mathrm{c}}$ & 29,98 \\
\hline $\begin{array}{l}\text { ALAL }(\mathrm{mmol} / \mathrm{dia}) \\
\text { MALLA }\end{array}$ & 1,12 & 0,88 & 0,34 & 75,04 \\
\hline $\begin{array}{l}\text { ALA:DP }(\%) \\
A L L A: P D(\%)\end{array}$ & 89,07 & 90,51 & 91,80 & 3,01 \\
\hline $\begin{array}{l}\mathrm{DP}(\mathrm{mmol} / \mathrm{dia}) \\
P D(\text { mmol/day })\end{array}$ & $364,11^{\mathrm{a}}$ & $297,11^{\mathrm{a}}$ & $174,80^{\mathrm{b}}$ & 23,05 \\
\hline $\begin{array}{l}\text { Pabs (mmol/dia) } \\
\text { absP (mmol/day) }\end{array}$ & $395,41^{\mathrm{a}}$ & $316,84^{\mathrm{a}}$ & $169,08^{b}$ & 25,34 \\
\hline $\begin{array}{l}\text { Nmic (g/dia) } \\
\operatorname{micN}(\text { g/day })\end{array}$ & $248,86^{\mathrm{a}}$ & $199,42^{\mathrm{a}}$ & $106,42^{b}$ & 25,34 \\
\hline $\begin{array}{l}\text { Efic }(\mathrm{g} \mathrm{PBmic} / \mathrm{kg} \text { NDT}) \\
\text { Efic }(g \text { mic } C P / \mathrm{kg} T D N)\end{array}$ & 128,78 & 128,82 & 98,67 & 18,67 \\
\hline $\mathrm{pH}$ & 6,24 & 6,54 & 6,78 & 3,63 \\
\hline
\end{tabular}

A proporção de alantoína em relação aos derivados de purina totais foi, em média, de 90,46\%. Valadares et al. (1999) reportaram que a proporção alantoína:DP total não foi afetada pelos níveis de concentrado, apresentando valores de 90,2 a 90,7\%, similares aos encontrados neste trabalho. Vagnoni et al. (1997) observaram média de 91,1\%.

Foram encontradas diferenças numéricas, embora não-significativas $(\mathrm{P}>0,05)$, na eficiência e na síntese de proteína microbiana entre os animais de alta e média produção. A maior produção microbiana está de acordo com o consumo mais elevado, o qual disponibilizou maior quantidade de substratos fermentáveis e elevou a taxa de passagem aumentando o arraste de microrganismos do rúmen. Em maiores taxas de passagem, a idade média dos microrganismos é reduzida (Van Soest, 1994), selecionando microrganismos com menor tempo de geração e menor utilização de substratos para mantença microbiana e diminuindo a predação e a reciclagem de nutrientes, aumentando a eficiência microbiana.

$\mathrm{Na}$ Tabela 5 são apresentadas as médias gerais do experimento obtidas em 24 horas de coleta total de urina ou estimadas pela amostra spot de urina. Ao agrupar todos os tratamentos, não foram detectadas diferenças entre as médias do volume urinário e da excreção de uréia e de derivados de purina obtidos pela coleta total ou estimados pela coleta spot. Conseqüentemente, não foram detectadas diferenças no fluxo e na eficiência de síntese de PB microbiana, logo, a coleta spot possibilitou estimar a excreção de DP e uréia em todos os níveis de produção de leite estudados.

Silva et al. (2001) e Oliveira et al. (2001), em estudo com vacas leiteiras consumindo dietas com níveis crescentes de uréia, também não encontraram diferenças entre as médias obtidas e estimadas para os mesmos parâmetros avaliados neste trabalho. Rennó et al. (2003) detectaram diferença no volume urinário de novilhos, mas não constataram diferença nos demais parâmetros avaliados pelas coletas spot ou total. Neste estudo, o volume urinário foi pouco correlacionado à excreção de compostos urinários, em decorrência da ampla variação da concentração desses compostos na urina, e, mesmo que o volume urinário tenha sido distinto entre as duas metodologias, a excreção de uréia e DP estimada pela amostra spot foi similar à obtida na coleta total.

Valadares et al. (1999), pela técnica da coleta spot, estimaram satisfatoriamente a excreção de derivados de purinas e outros metabólitos urinários em diferentes dietas. Entretanto, Chen et al. (1995) reportaram que a coleta spot poderia não ser suficientemente sensível para possibilitar a detecção de pequenas diferenças entre tratamentos. 
Tabela 5 - Médias e probabilidades $(\mathrm{P})$ obtidas em coleta total de urina e estimadas pela amostra spot de urina, do volume urinário (VUR), das excreções de $\mathrm{N}$ uréico na urina (NUU), de alantoína (ALA), de ácido úrico (AcU) e de derivados de purina totais (DP), das purinas microbianas absorvidas (Pabs), dos compostos nitrogenados microbianos (Nmic) e da eficiência microbiana (Efic)

Table 5 - Means and probabilities $(P)$, obtained by total urine collection and estimated by spot urine sampling, for urinary volume (UV), urinary excretions of urea $N(U N U)$, allantoin (ALLA), uric acid $(U A C)$ and purine derivatives $(P D)$, absorbed microbial purines (absP), microbial nitrogen synthesis (micN) and microbial efficiency (Efic) according to different milk yield levels

\begin{tabular}{lccc}
\hline & $\begin{array}{c}\text { Coleta total } \\
\text { Total collection }\end{array}$ & $\begin{array}{c}\text { Coleta spot } \\
\text { Spot sampling }\end{array}$ & $\mathrm{P}$ \\
\hline $\begin{array}{l}\text { VUR (L/dia) } \\
\text { UV (L/day) }\end{array}$ & 17,84 & 20,69 & $\mathrm{n} \mathrm{s}$ \\
$\begin{array}{l}\text { NUU (g/dia) } \\
\text { UNU (g/day) }\end{array}$ & 106,93 & 111,04 & $\mathrm{n} \mathrm{s}$ \\
ALA (mmol/dia) & 250,79 & 254,60 & $\mathrm{n} \mathrm{s}$ \\
$\begin{array}{l}\text { ALLA (mmol/day) } \\
\text { AcU (mmol/dia) }\end{array}$ & 27,10 & 27,82 & $\mathrm{n} \mathrm{s}$ \\
$\begin{array}{l}\text { UAc (mmol/day) } \\
\text { DP (mmol/dia) }\end{array}$ & 278,67 & 283,20 & $\mathrm{n} \mathrm{s}$ \\
$\begin{array}{l}P D(\text { mmol/day) } \\
\text { Pabs (mmol/dia) } \\
\text { absP (mmol/day) }\end{array}$ & 293,78 & 299,11 & $\mathrm{n} \mathrm{s}$ \\
$\begin{array}{l}\text { Nmic (g/dia) } \\
\text { micN (g/day) }\end{array}$ & 184,90 & 188,25 & $\mathrm{n} \mathrm{s}$ \\
$\begin{array}{l}\text { Efic (g PBmic/kg NDT) } \\
\text { Efic (g micCP/kg TDN) }\end{array}$ & 118,76 & 124,23 & $\mathrm{n} \mathrm{s}$ \\
\hline
\end{tabular}

ns Não-significativo a $5 \%$ de probabilidade pelo teste t.

ns Not significant at $5 \%$ of probability by t test.

Não foram observadas diferenças entre as purinas microbianas absorvidas nos animais de alta, média e baixa produção utilizando-se as equações propostas por Orellana Boero et al. (2001) (respectivamente, 395,41; 316,84 e $169,08 \mathrm{mmol} / \mathrm{dia}$ ) ou Gonzalez-Ronquillo et al. (2003) (respectivamente,433,33;338,31 e 153,39 mmol/dia). Orellana Boero et al. (2001), em estudo com vacas não-lactantes, estimaram que a excreção endógena de purinas foi de $0,236 \times \mathrm{PV}^{0,75}$ $\mathrm{mmol} /$ dia e a recuperação das purinas absorvidas como derivados de purinas foi de 0,84 . Posteriormente, GonzalezRonquillo et al. (2003), em experimento com vacas lactantes, relataram a existência de fração endógena de $0,512 \times \mathrm{PV}^{0,75}$ $\mathrm{mmol} /$ dia, superior à estimada por Orellana Boero et al. (2001), mas a recuperação das purinas absorvidas como derivados de purinas na urina e no leite foram inferiores (em média 0,56 e 0,70 nas vacas com 10 ou 33 semanas de lactação, respectivamente). Portanto, quando calculada segundo Gonzalez-Ronquillo et al. (2003), embora a contribuição endógena tenha sido superior ao dobro da reportada por Orellana Boero et al. (2001), a recuperação das purinas absorvidas foi inferior $(0,70)$, logo, as purinas absorvidas calculadas utilizando-se as duas equações foram próximas.
Deve-se ressaltar que as excreções de creatinina obtidas com vacas em lactação no Brasil têm sido bastante próximas de $24 \mathrm{mg} / \mathrm{kg}$ de peso vivo (Pina et al., 2006, citando dados de Pereira em 2003 - 24,4; Oliveira et al., 2001 - 23,41; Silva et al., $2001-23,60)$.

\section{Conclusões}

O consumo está diretamente relacionado à produção de leite. Quando o fornecimento de concentradoé proporcional à produção de leite, esta produção eleva o consumo de nutrientes, a produção microbiana, a concentração de amônia no rúmen e a excreção urinária de compostos nitrogenados, mas não influencia a digestibilidade da MS dietética.

A presença de cinzas e proteína na FDN ocasiona subestimativa da digestibilidade da FDN e superestimativa dos CNF, mas não afeta o teor de NDT.

As concentrações de NUS e NUL são correlacionadas à excreção urinária de $\mathrm{N}$ e à concentração de amônia no rúmen, podendo auxiliar no balanceamento protéico de dietas, contudo, a concentração ótima de NUS ou de NUL varia com o nível de produção de leite.

A coleta spot pode ser utilizada para estimar a excreção diária de derivados de purinas e de uréia na urina em vacas, independentemente do nível de produção.

\section{Literatura Citada}

BRODERICK, G.A. Use of milk urea as an indicator of nitrogen utilization in lactating dairy cow. Washington: USDA Agricultural Research Service; US Dairy Forage Research Center, 1995. 122p. (Research Summaries).

BRODERICK, G.A.; MERCHEN, N.R. Markers for quantifying microbial protein synthesis in the rumen. Journal of Dairy Science, v.75, n.9, p.2618-2632, 1992.

BUTLER, W.R.; Review: effect of protein nutrition on ovarian and uterine physiology in dairy cattle. Journal of Dairy Science, v.81, n.9, p.2533-2539, 1998.

CHEN, X.B.; GOMES, M.J. Estimation of microbial protein supply to sheep and cattle based on urinary excretion of purine derivatives - an overview of technical details. Bucksburnd: Rowett Research Institute; International Feed Resources Unit, 1992. 21p. (Occasional publication).

CHEN, X.B.; MEJIA, A.T.; KYLE, D.J. et al. Evaluation of the use of the purine derivative: creatinine ratio in spot urine and plasma samples as an index of microbial protein supply in ruminants: studies in sheep. Journal of Agricultural Science, v.125, p.137-143, 1995.

CHIZZOTTI, M.L. Avaliação da casca de algodão para novilhos de origem leiteira e determinação da excreção de creatinina e produção de proteína microbiana em novilhas e vacas leiteiras. Viçosa, MG: Universidade Federal de Viçosa, 2004. 132p. Dissertação (Mestrado em Zootecnia) Universidade Federal de Viçosa, 2004.

COCHRAN, R.C.; ADAMS, D.C.; WALLACE, J.D. et al. Predicting digestibility diets with internal markers: Evaluation of four potential markers. Journal of Animal Science, v.63, p.14761483, 1986. 
COELHO DA SILVA, J.F.; LEÃO, M.I. Fundamentos de nutrição dos ruminantes. Piracicaba: Livroceres, 1979. 380p.

FUJIHARA, T.; ØRSKOV, E.R.; REEDS, P.J. et al. The effect of protein infusion on urinary excretion of purine derivatives in ruminants nourished by intragastric nutrition. Journal of Agricultural Science, v.109, n.1, p.7-12, 1987.

GONDA, H.L.; LINDBERG, J.E. Effect of diet on milk allantoin and its relationship with urinary allantoin in dairy cows. Journal of Dairy Science, v.80, p.364-373, 1997.

GONZALEZ-RONQUILLO, M.; BALCELLS, J.; GUADA, J.A.; VICENTE, F. Purine derivative excretion in dairy cows: Endogenous excretion and the effect of exogenous nucleic acid supply. Journal of Dairy Science, v.86, n.4, p.1282-1291, 2003

HALL, M.B. Calculation of non-structural carbohydrate content of feeds that contain non-protein nitrogen. Gainesville: University of Florida, 2000. p.A-25. (Bulletin 339).

ÍTAVO, L.C.V.; VALADARES FILHO, S.C.; SILVA, F.F. et al. Comparação de indicadores e metodologia de coleta para estimativas de produção fecal e fluxo de digesta em bovinos. Revista Brasileira de Zootecnia, v.31, n.4, p.1833-1839, 2002

JONKER, J.S.; KOHN, R.A.; ERDMAN, R.A. Using milk urea nitrogen to predict nitrogen excretion and utilization efficiency in lactating dairy cows. Journal of Dairy Science, v.81, n.10, p.2681-2692, 1998.

KAUFFMAN, A.J.; ST-PIERRE, N.R. The relationship of milk urea nitrogen to urine nitrogen excretion in Holstein and Jersey cows. Journal of Dairy Science, v.84, p.2284-2294, 2001.

NATIONAL RESEARCH COUNCIL - NRC. Nutrient requirements of dairy cattle. 7.ed. Washington, D.C.: National Academic Press, 2001. 381p.

OLIVEIRA, A.S.; VALADARES, R.F.D.; VALADARES FILHO, S.C. et al. Produção de proteína microbiana e estimativas das excreções de derivados de purinas e de uréia em vacas lactantes alimentadas com rações contendo diferentes níveis de compostos nitrogenados não-protéicos. Revista Brasileira de Zootecnia, v.30, n.5, p.1621-1629, 2001

ORELLANA BOERO, P.; BALCELLS, J.; MARTÍN-ORÚE, S.M. et al. Excretion of purine derivates in cows: endogenous contribution and recovery of exogenous purine bases. Livestock Production Science, v.68, p.243-250, 2001

PINA, D.S.; VALADARES FILHO, S.C.; VALADARES, R.F.D. et al. Síntese de proteína microbiana e concentrações de uréia em vacas alimentadas com diferentes fontes de proteína. Revista Brasileira de Zootecnia, v.35, n.4, p.1552-1559, 2006

PREGNOLATTO, W.; PREGNOLATTO, N.P. Normas analíticas do instituto Adolfo Lutz - métodos químicos e físicos para análise de alimentos. 3.ed. São Paulo, 1985. v.1, 533p.

RENNÓ, L.N.; VALADARES FILHO, S.C.; PAULINO, M.F. et al. Indicadores interno ou externo e efeito da contaminação da fibra em detergente neutro sobre a digestibilidade aparente total em novilhos. In: REUNIÃO ANUAL DA SOCIEDADE BRASILEIRA DE ZOOTECNIA, 39., 2002, Recife. Anais... Recife: Sociedade Brasileira de Zootecnia, 2002. (CD-ROM).

RENNÓ, L.N.; VALADARES FILHO, S.C.; VALADARES, R.F.D. et al. Níveis de proteína na ração de novilhos de quatro grupos genéticos: estimativa da produção de proteína microbiana por intermédio dos derivados de purinas na urina. In: REUNIÃO ANUAL DA SOCIEDADE BRASILEIRA DE ZOOTECNIA, 40.
2003, Santa Maria. Anais... Santa Maria: Sociedade Brasileira de Zootecnia, 2003. (CD-ROM)

SANTOS, G.T.; CAVALIERI, F.L.B.; MODESTO, E.C. Recentes avanços em nitrogênio não protéico na nutrição vacas leiteiras. In: SINLEITE - NOVOS CONCEITOS EM NUTRIÇÃO, 2., 2001, Lavras. Anais... Lavras: Universidade Federal de Lavras, 2001. p.225-248.

SILVA, D.J.; QUEIROZ, A.C. Análise de alimentos (métodos químicos e biológicos). 3.ed. Viçosa: Editora UFV, 2002. 235p.

SILVA, R.M.N.; VALADARES, R.F.D.; VALADARES FILHO, S.C. et al. Uréia para vacas em lactação. 2. Estimativas do volume urinário, da produção microbiana e da excreção de uréia. Revista Brasileira de Zootecnia, v.30, n.6, p.1948-1957, 2001.

SNIFFEN, C.J.; O'CONNOR, J.D.; Van SOEST, P.J. et al. A net carbohydrate and protein system for evaluating cattle diets: II. Carbohydrate and protein availability. Journal of Animal Science, v.70, n.11, p.3562-3577, 1992.

TYRRELL, H.F.; REID, J.T. Prediction of the energy value of cow's milk. Journal of Dairy Science, v.48, n.9, p.1215$1223,1965$.

UNIVERSIDADE FEDERAL DE VIÇOSA - UFV. SAEG - Sistema de análises estatísticas e genéticas. Versão 8.0. Viçosa, MG: 1998. 150p. (Manual do usuário).

VAGNONI, D.B.; BRODERICK, G.A.; CLAYTON, M.K. et al. Excretion of purine derivatives by Holstein cows abomasally infused with incremental amounts of purines. Journal of Dairy Science, v.80, n.8, p.1695-1702, 1997.

VALADARES, R.F.D.; BRODERICK, G.A.; VALADARES FILHO, S.C. et al. Effect of replacing alfafa silage with high moisture corn on ruminal protein synthesis estimated from excretion of total purine derivatives. Journal of Dairy Science, v.82, n.12, p.2686-2696, 1999.

VALADARES, R.F.D.; GONÇALVES, L.C.; RODRIGUEZ, N.M. et al. Níveis de proteína em dietas de bovinos. 4. Concentrações de amônia ruminal e uréia plasmática e excreções de uréia e creatinina. Revista Brasileira de Zootecnia, v.26, n.6, p.1270-1278, 1997.

Van SOEST, P.J. Nutritional ecology of the ruminant. 2.ed. London: Comstock Publishing Associates, 1994. 476p.

VIEIRA, P.F. Efeito do formaldeído na proteção de proteínas e lipídios em rações para ruminantes. Viçosa, MG: Universidade Federal de Viçosa, 1980. 98p. Tese (Doutorado em Zootecnia) - Universidade Federal de Viçosa, 1980.

WEISS, W.P. Energy prediction equations for ruminant feeds. In: CORNELL NUTRITION CONFERENCE FOR FEED MANUfACTURERS, 61., 1999, Ithaca. Proceedings... Ithaca: Cornell University, 1999. p.176-185. 